Www.jmscr.igmpublication.org

Impact Factor (SJIF): 6.379

Index Copernicus Value: 79.54

ISSN (e)-2347-176x ISSN (p) 2455-0450

crossrefDOI: https://dx.doi.org/10.18535/jmscr/v6i12.168

Journal Of Medical Science And Clinical Research

IGM Publication

An Official Publication of IGM Publication

\title{
Prevalence of Hypothyroidism in Adults in Kashmir Valley
}

\author{
Authors \\ Dr Nazir Ahmad Malla, Dr Peerzada Mohammad Shafi \\ Corresponding Author \\ Dr Peerzada Mohammad Shafi \\ Email: peerzadashafi@gmail.com, Cell: +91-9797859030
}

\begin{abstract}
Background: Hypothyroidism is one of the most common and treatable endocrine disease in which there is insufficient amount of thyroid hormones in body. Iodine deficiency remains the most common cause of hypothyroidism worldwide. The food grown in soil of hilly areas and around rivers is iodine deficient due to leaching out of iodine from soil, resulting in increased incidence of hypothyroidism in these areas.

Objective: To estimate the prevalence of hypothyroidism in adults in Kashmir valley

Methodology: This cross-sectional study was conducted in Kashmir valley. Kashmir valley was divided into three zones. North south and central zones to study the prevalence of hypothrodism among adult population of Kashmir valley. Hypothyroidism was diagnosed as elevated TSH with normal or low T4.

Results: A total of 4770 adults with more than 20 years of age were studied for hypothyroidism of which 2130 were males and 2640 were females. The overall prevalence of hypothyroidism was found to be 16.18 per cent. Prevalence of hypothyroidism was more among rural population $(18.45 \%)$ as compared to urban population (11.63\%).Prevalence of hypothyroidism was more as age of patients increased.It was more among females than males.

Conclusion: Hypothyroidism is a growing problem in this part of world. It is more common in rural than in urban, more common among females as compared to males. This high prevalence of Hypothyroidism is a cause of concern since it is a multisystem disorder and is associated with profound morbidity and mortality.
\end{abstract}

\section{Introduction}

Thyroid gland is a very important endocrine gland which is concerned with rate of metabolism, blood calcium levels and affects on growth and development in mammals ${ }^{1}$. The thyroid gland is not essential for life but its absence causes mental and physical slowing, poor resistance to cold and in children mental retardation and dwarfism ${ }^{2}$. Two kinds of diseases are seen because of malfunctioning of thyroid gland; under activity leading to hypothyroidism and over activity leading to hyperthyroidism or thyrotoxicosis. Among the two hypothyroidism is more common.
Reduced production of thyroid hormone is the central feature of clinical state termed hypothyroidism ${ }^{3,4}$. Permanent loss or destruction of the thyroid, through processes such as autoimmune destruction or irradiation injury, is described as primary hypothyroidism. Hypothyroidism due to transient or progressive impairment of hormone biosynthesis is typically associated with compensatory thyroid enlargement. Central or secondary hypothyroidism, due to insufficient stimulation of a normal gland, is the result of hypothalamic or pituitary disease or defects in the thyroid- 
stimulating hormone (TSH) molecule. Transient or temporary hypothyroidism can be observed as a phase of sub acute thyroiditis. Primary hypothyroidism is the etiology in approximately 99\% of cases of hypothyroidism, with less than $1 \%$ being due to TSH deficiency or other causes. Iodine deficiency remains the most common cause of hypothyroidism worldwide ${ }^{5}$. Hypothyroidism is one of the most common and treatable endocrine disease in which there is insufficient amount of thyroid hormones ${ }^{6}$.

Hypothyroidism is a graded phenomenon, ranging from very mild case in which bio chemical abnormalities are present but the individual hardly notices symptoms and signs of thyroid hormone deficiency, to very severe cases in which the danger exists to slide into a life-threatening Myxedema coma. In the development of Primary Hypothyroidism, the transition from the euthroid to hypothyroidism state is first detected by slightly increased serum TSH, caused by a minor decrease in thyroidal secretion of $\mathrm{T} 4$ concentrations. The reason for maintaining serum $\mathrm{T} 4$ value within the reference range is the exquisite sensitivity of pituitary throtroph for even very small decrease of Serum T4 as exemplified by log-linear relationship between TSH and $\mathrm{T}^{7}{ }^{7}$ A further decline in $\mathrm{T} 4$ secretion results in $\mathrm{T} 4$ values below the lower normal limit and even higher TSH values, but $\mathrm{T} 3$ concentration remain within the reference range. It is only in the last stage that subnormal serum T3 concentration are found, when $\mathrm{T} 4$ has fallen to really very low values associated with markedly elevated TSH concentration. This is a graded phenomenon, in which the first stage of subclinical hypothyroidism may progress via mild hypothyroidism towards overt hypothyroidism.

\section{Grades of Hypothyroidism}

\begin{tabular}{|l|c|c|c|c|}
\hline Grade 1 & $\begin{array}{c}\text { Subclinical } \\
\text { Hypothyroidism }\end{array}$ & TSH + & FT4 N & T3N \\
\hline Grade 2 & Mild Hypothyroidism & TSH + & FT4- & T3 N \\
\hline Grade 3 & $\begin{array}{c}\text { Overt } \\
\text { Hypothyroidism }\end{array}$ & TSH + & FT4 - & T3 - \\
\hline
\end{tabular}

+ , above upper normal limit; $\mathrm{N}$, within normal reference range;below lower normal limit.

\section{Aims and Objective}

To estimate the prevalence of hypothyroidism in adults in Kashmir valley.

\section{Material and Methods}

This study was undertaken to determine what proportion of adults are hypothyroid. The study group included subjects above 20 years of age irrespective of gender. The study was planned as cross-sectional field survey which measures the prevalence of disease. Jammu and Kashmir State is the northern most state of India with an overall population of 1.25 crores. Kashmir is one of the three divisions of the state with majority of population i.e. 70 lakhs residing in 10 districts.

Sampling frame: Multistage sampling technique was adopted. Kashmir valley was divided into three zones viz, north, central and south. The North zone comprising of districts Kupwara, Baramulla and Bandipora. The central zone comprising of districts Srinagar, Ganderbal and Budgam and the south zone comprised of Anantnag, Pulwama, Shopian and Kulgam districts. One district was selected from each zone after random sampling. Baramulla with population of 11.6 lakh from North Zone, Srinagar with population of 12.3 lakh from central Zone and Anantnag with population of 11.7 lakh from south Zone. In each selected district lying listing of all villages was selected. Among the selected villages lying listing of the households was done and 5\% of the households were selected. From each household one member was selected by a simple random technique.

Sample size: Sampling size was calculated using Epo info 3.2.1.008 statistical software of CDC Atlanta. Based on pretesting the expected frequency of hypothyroidism was calculated with $20 \%$ as worst acceptable value and at $95 \%$ confidence interval (C1) level, the sample size was calculated.

Criteria for hypothyroidism: All the subjects enrolled in the study were tested for serum TSH and serum $\mathrm{T} 4$ by new automated immunochemiluminometric assay (ICMA). 
Subclinical hypothyroidism was defined as elevated TSH $(\mathrm{TSH}>4.5 \mu \mathrm{IU} / \mathrm{l})$ with normal T4 (T4 4.5-13 $\mu \mathrm{gm} / \mathrm{dl})^{8}$. While as clinical hypothyroidism was defined as elevated TSH with low T4.

Statistical Analysis: A statistical analysis done by using statistical package for social sciences (SPSS). Proportional chi-square test and Pearson's chi-square test was applied for the statistical analysis of the data. A two tailed p-value was used for calculating statistical significance. A p-value of less than 0.05 was taken as statistically significant.

\section{Results}

A total No. of 4770 adults of more than 20 years of age participated in the study. $2130(44.65 \%)$ participants were males and $2640(55.35 \%)$ were females. $3180(66.67 \%)$ were from rural areas and $1590(33.33 \%)$ were from urban areas. $15.73 \%$ (1146) were above 50 years of age; $48.01 \%$ (2290) were in age group of 40-50 years. Prevalence of hypothyroidism was found to be $16.18 \%$ (772).Among them $13.38 \%$ (285) were males and $18.45 \%$ (487) were females with a $\mathrm{p}$ value of $<0.0001$ which is statistically significant. $714(14.97 \%)$ of participants were having subclinical hypothyroidism and $58(1.21 \%)$ were having overt hypothyroidism. Among the male hypothyroid, $76.14 \%$ (285) were having subclinical hypothyroidism and $23.86 \%$ (68) were having overt hypothyroidism. Among the female hypothyroid participants $94.56 \%$ (460) were having sub-clinical hypothyroidism and $5.54 \%$ (27) were having overt hypothyroidism. The study showed that hypothyroidism is more common in female population and relation between hypothyroidism and female sex is statistically significant with $\mathrm{p}$ value less than 0.001 .

In urban male participants, $9.07 \%$ (68) were hypothyroid and $90.93 \%$ (682) were having normal TSH. $13.93 \%$ of female urban population was having high serum TSH and $86.07 \%$ of female urban population were having normal TSH. The study shows statistically significant prevalence in urban females as compared to urban males with $\mathrm{p}$ value less than $0.0025 .15 .73 \%$ of the male rural population were hypothyroid, $84.27 \%$ of male rural population were normal. $20.56 \%$ of female rural participants were hypothyroid and $79.44 \%$ of female rural population were normal. Hypothyroidism in rural population is more common in females and relationship is statistically significant with $\mathrm{p}$ value of 0.0005 .

Table 1 Distribution of study population as per Age, Residence, Serum TSH Levels, Serum FT4

\begin{tabular}{|l|c|c|c|c|c|c|c|}
\hline \multirow{2}{*}{ Geography } & \multicolumn{2}{|c|}{ Male } & \multicolumn{2}{c|}{ Female } & \multicolumn{2}{c|}{ Total } \\
\cline { 3 - 8 } & No. & \% & No. & \% & No. & $\%$ \\
\hline \multirow{3}{*}{ Geography } & Rural & 1380 & 28.93 & 1800 & 37.74 & 3180 & 66.67 \\
\cline { 2 - 8 } & Urban & 750 & 15.72 & 840 & 17.61 & 1590 & 33.33 \\
\hline \multirow{4}{*}{ Age in Years } & $20-30$ & 238 & 04.99 & 286 & 05.99 & 524 & 10.98 \\
\cline { 2 - 8 } & $30-40$ & 524 & 10.98 & 620 & 13.00 & 1206 & 25.28 \\
\cline { 2 - 8 } & $40-50$ & 859 & 18.01 & 1280 & 26083 & 2290 & 48.01 \\
\cline { 2 - 8 } & $>50$ & 509 & 10.67 & 454 & 09.52 & 1146 & 15.73 \\
\hline \multirow{3}{*}{ Serum TSH } & Low & 14 & 00.66 & 42 & 1.59 & 56 & 1.18 \\
\cline { 2 - 8 } & Normal & 1831 & 85.96 & 2111 & 79.96 & 3942 & 82.64 \\
\cline { 2 - 8 } & High & 285 & 13.38 & 487 & 18.45 & 772 & 16.18 \\
\hline
\end{tabular}

Table 2 Types of hypothyoridism

\begin{tabular}{|l|c|c|}
\hline Hypothyroidism types & No. of Patients & Percentage \\
\hline Subclinical & 714 & 14.97 \\
\hline Overt & 58 & 1.21 \\
\hline Normal & 3998 & 83.82 \\
\hline Total & 4770 & 100 \\
\hline
\end{tabular}


Table 3 Distribution of hypothyroidism in urban and rural population

\begin{tabular}{|l|c|c|c|c|c|c|}
\hline \multirow{2}{*}{ Sr. TSH } & \multicolumn{2}{|c|}{ Male } & \multicolumn{2}{c|}{ Female } & \multicolumn{2}{c|}{ Total } \\
\cline { 2 - 7 } URBAN & No. & $\%$ & No. & \% & No. & \% \\
\hline High & 68 & 9.07 & 117 & 13.93 & 185 & 11.64 \\
\hline Normal & 682 & 90.93 & 723 & 86.07 & 1405 & 88.36 \\
\hline RURAL & 217 & 15.72 & 370 & 20.56 & 587 & 18.46 \\
\hline High & 1163 & 84.27 & 1430 & 79.44 & 2593 & 81.54 \\
\hline Normal
\end{tabular}

Table 4 Age wise Distribution hypothyroidism

\begin{tabular}{|c|c|c|c|c|c|c|}
\hline \multirow{2}{*}{ AgeGroups (years) } & \multicolumn{2}{|c|}{ Hypothyroid } & \multicolumn{2}{|c|}{ Normal } & \multicolumn{2}{|c|}{ Total } \\
\hline & No. & $\%$ & No. & $\%$ & No. & $\%$ \\
\hline \multicolumn{7}{|l|}{ MALES } \\
\hline $20-30$ & 022 & 09.24 & 216 & 90.76 & 238 & 100 \\
\hline $30-40$ & 059 & 11.26 & 465 & 88.74 & 524 & 100 \\
\hline $40-50$ & 112 & 13.04 & 747 & 86.96 & 859 & 100 \\
\hline$>50$ & 092 & 18.07 & 417 & 81.93 & 509 & 100 \\
\hline \multicolumn{7}{|l|}{ FEMALES } \\
\hline $20-30$ & 030 & 10.49 & 256 & 89.51 & 286 & 100 \\
\hline $30-40$ & 096 & 15.48 & 524 & 84.52 & 620 & 100 \\
\hline $40-50$ & 247 & 19.30 & 1033 & 80.70 & 1280 & 100 \\
\hline$>50$ & 114 & 25.11 & 340 & 74.89 & 454 & 100 \\
\hline
\end{tabular}

\section{Discussion}

The present study was conducted in the Kashmir valley. A total of 4770 adults aged 20 years and above were studied and screened for hypothyroidism. Among the study population $2130(44.65 \%)$ were males and $2640(55.35 \%)$ were females.

The overall prevalence of hypothyroidism in this study population was $16.18 \% \quad$ (772) with subclinical accounting for 714(14.97\%) and overt accounting for $58(1.21 \%)$. Barl et $\mathrm{al}^{9}$. In one of the studies conducted at BPKIHS in 2002, studied a total of 599 cases were studied during a single year and the cases with raised TSH were $17.19 \%$ with slightly higher prevalence among Terrai castes $(17.66 \%)$ when compared with hill castes $(15.17 \%)$. The prevalence of hypothyroidism in various studies from around the world shows considerable variation and its current prevalence ranges from as low as $1 \%$ to as high as $20 \%$ for subclinical and $1.2 \%$ for overt hypothyroidism. Estimates of the prevalence of hypothyroidism depends upon methodological factors, classification of hypothyroidism and composition of the community examined by age, ethnicity, and gender, making comparisons between studies of limited values. Tunbridge et $\mathrm{al}^{7}$, were the first to provide a reliable estimate of the prevalence of hypothyroidism in the general adult population. They found out that $10.3 \%$ and $0.3 \%$ were suffering from subclinical and overt hypothyroidism, respectively. Another study from Tehran, Iran, on individuals more than 20 years of age demonstrated that $0.35 \%$ of individuals were overt ad $2.2 \%$ were subclinical hypothyroid 44 .

Our study showed the prevalence of subclinical hypothyroidism $714 \quad(14.97 \%)$ and overt hypothyroidism $58(01.21 \%)$ and our study results were consistent with the previous studies viz.; Baraiet $\mathrm{al}^{8}$ and Tunbridge et $\mathrm{al}^{7}$.

Another study from northern Japan, where iodine intake is high, revealed that $0.7 \%$ of men and $3.1 \%$ of women were overt hypothyroid ${ }^{10}$.The prevalence of elevated TSH among Colorado men ranging from $3 \%$ to $16 \%$ and among women ranging from $4.0 \%$ to $21 \%{ }^{11}$.

In our study the prevalence of hypothyroidism was more common among women as compared to men and the results were consistent with the previous studies viz.; Colorado study ${ }^{11}$ and Konno $\mathrm{N}$, et $\mathrm{al}^{10}$ study. 
The prevalence of subclinical hypothyroidism is about $5.3 \%$ in the USA and $5-10 \%$ in most countries $^{7,10,12,13}$ in western Europe ${ }^{14}$. Elevated serum TSH levels were found in $1.2 \%$ of men and women in Germany.

Gender is most positively associated with hypothroidism $^{15}$. In our study, 285 (13.38\%) were hypothyroid among 2130 studied males and 487 (18.45\%) were hypothyroid among 2640 studied females consistent with prior studies ${ }^{15}$. The prevalence of hypothyroidism was found to be higher in women than in men, and the difference was more evident in overt hypothyroidism where the rate for women was more than six times higher than that for men.

In one study by Aminorroaya $\mathrm{A}$ et $\mathrm{al}^{15}$, prevalence rates of hypothyroidism were higher in women (4.2\% for overt and $8.6 \%$ for subclinical hypothyroidism) than men (1.6\% for overt and $3.1 \%$ for subclinical hypothyroidism)

The prevalence of hypothyroidism was higher in older people compared to younger. Tunbridge et $\mathrm{al}^{7}$ found that $7.5 \%$ of women and $2.8 \%$ of men of all age groups in Wickham, England had serum TSH levels greater than $6 \mu \mathrm{Iu} / \mathrm{l}$.

Virtually all studies report higher prevalence rates for hypothyroidism in women ${ }^{16,17,18,19,20,21}$. Thyroid disease is remarkably more prevalent in women than in men with a female/male ratio3.512 . $^{22,23,24,25,26}$

Age was strongly associated with hypothyroidism as has been reported previously ${ }^{2,7}$ and present study revealed that prevalence of hypothyroidism increases with age from $9.24 \%$ in the age group of $20-30$ years, $11.26 \%$ in the age group of 30-40 years, $13.0 \%$ in the age group of $40-50$ years and $18.07 \%$ in the age group of $>50$ years in males where as in females the prevalence of hypothyroidism increased with age from $10.40 \%$ in the age group of 20-30 years, $15.48 \%$ in the age group of 30-40 years, $19.30 \%$ in the age group of $40-50$ years and $25.11 \%$ in the age group $>50$ years. Study conducted by Canaris GJ et $\mathrm{al}^{17}$ in subjects aged 18 years to greater than 74 years old revealed that the prevalence of hypothyroidism increased with increasing age with $3 \%$ in the age group 18-24 years, to $16 \%$ in the age group greater than 74 years in men and $4 \%$ in the age group 18-24 years, to $21 \%$ in women aged greater than 74 years. In many studies, it was observed that the proportion of subjects with an elevated TSH level were greater among women than men and increased with advancing age. ${ }^{16,17,18,19,20,21}$.

\section{Conclusion}

In conclusion, we observed that hypothyroidism is a growing problem in this part of the world. It is more common in rural than in urban population with females predominance same as with other endocrine diseases. This high prevalence of hypothyroidism is a cause of concern since it is a multisystem disorder and is associated with profound morbidity and mortality. Awareness programs must be initiated and control and prevention programs need to be adopted to decrease the prevalence of hypothyroidism in the Kashmiri population.

\section{Bibliography}

1. Ganong WF. Review of Medical Physiology. 22nd Edition Singapore: McGraw Hill 2005; p 317-32

2. Kapil U. Sohal KS. Sharma TD. Tandon M. Assessment of Iodine Deficiency Disorders using the 30 cluster approach in district kangra Himachal Pardesh, Indian J Trop Pediatr 2000; 46: 264-6.

3. Dayan CM, Daniels GH. Chronic autoimmune thyroiditis. N Engl Med 1996; 335:99-107.

4. Pearce EN, Farwell AP, Braveman LE. Thyroiditis. NEngl J Med 2003; 348:2646-55.

5. Jameson LL, Weetman AP. Disorders of the Thyroid Gland. Harrison's Principle of Internal Med. 17th Edition, 2005; 335;2242247.

6. Unachak, Dejkhamron P. Primary Congenital Hypthroidism: Clinical characteristics and etiological study. J. Med Assoc Thai 2004; 37: 642-7. 
7. Tunbrodge WM, Hall R, Appleton D, Brewis $\mathrm{M}$, Clark F,et al. The spectrum of thyroid disease in a community: the Whicham Survey. ClinEndocrinol (Oxf). 1977 Dec; 7 (6): 481-493.

8. Aoki Y, Belin RM, Clickner R, Jeffries R, Philips I, Mahaffey KR Serum TSH and total T4 in the United States population and their association with participant characteristics: National Health and Nutrition Examination Survey (NHANES 1999-2002). Thyroid, Dec 2007; 17(12):1211-23.

9. Baral N, Lamsal M, Komer BC, Koirala S. Thyroid Dysfunction in Eastern Nepal. South East Asian J Trop Med public health 2002;33(3):638-41.

10. Canaris GJ, Neil R, Manowitz, Gilbert Mayer, Chester Ridgway. The Colorado Thyroid Disease Prevalence Study. Arch Intern Med. 2000; 160:526-534.

11. Ray A, Biswas U, Mukherjee A, Sarker KC, SamajdarK and Mukherjee G. Assessment of Iodine and Non-Iodine Deficiency Hypothyroidism in women of Reproductive ages in Sub-Himalayan plains of West Bengal Indian J PhysiolPhymacol 2009;53(4):359364.

12. Krysiak R, Okopien B, Hermen ZS. Subclinical thyroid disorders. Pol MerkurLekarski, 2006;21:573-578.

13. Galofre JC, Garcia-Mayor RV, Fluiters E, Fernandes-Calvet L, RegoA, Paramo C, et al. Incidence of different forms of thyroid dysfunction and its degrees in an iodinesufficient area. Thyroidology. 1994;6:49-54.

14. Hollowell JG, Staehlin NW, Flanders WD, Hannon WH, Gunter EW, Spencer CA, et al. Serum TSH, T4 and thyroid antibodies in the United states Population (1988 to 1994): The National Health and Nutritional Examination Survey (NHANES III). J ClinEndocrinolMetab. 2002;87:489-499.

15. Raterman HG, van Halm VP, Voskuyl AE, Simsek S, Dijkmans BAC and Nurmohamed MT. Rheumatoid arthritis is associated with a high prevalence of hypothyroidism that amplifies its cardiovascular risk. Annals of the Rheumatic Disease 2008; 67:229-232

16. Vaderpump MPJ, Tunbirdge WMG. The epidemiology of thyroid diseases. In: Braverman LE, Utiger RD, eds. Werner and Inagbar's the thyroid. Philadelphia: Lippincott-Raven; 2000:467-473.

17. Eggersten R, Petersen K, Lundberg PA, Nystrom E, Lindstedt G. Screening for thyroid disease in a primary care unit with a thyroid stimulating hormone assay with a low detection limit. BMJ, 1988; 297:1586-1592.

18. Sawin CT, Chopra D, Azizi F, Mannix JC, Bacharach P. The aging thyroid: Increased prevalence of elevated serum thyrotropin levels in the elderly. JAMA 1979; 242(3): 247-250.

19. Sawin CT, Castelli WP, Hershman JM, McNamara P, Bacharach P. The aging thyroid: thyroid deficiency in the Framingham study, Arch Intern Med. 1985; 145: 1386-1388.

20. Okamura K, Ueda K, Sone $\mathrm{H}$, et al. A sensitive thyroid stimulation hormone assay for screening of thyroid functional disorder in elderly Japanese. J Am Geriatr. Soc. 1989; 37:317-322.

21. Livingston EH, Hershman JM, Sawin CT, Yoshikawa TT. Prevalance of thyroid disease and abnormal thyroid tests in older hospitilised and ambulatory persons. I am Geriatr Soc. 1987; 35:109-114.

22. Konno N, Makita H, Yuri K, LIzuka N, Kawasaki K Association between dietary iodine intake and prevalence of subclinical hypothyroidism in the regions of Japan. J ClinEndocrinolMetab 1994;78:393-397.

23. Vanderpump MP, Tunbridge WM, French JM et al. The incidence of thyroid disorders in the community: a twenty- year follow-up of the Wickham Survey. ClinEndocrinol 1995;43(1):55-68.

24. Wang C, Crapo LM. The epidemiology of thyroid diseases and implications for 
screening. EndocrinolMetabClin North Am 1997;26:180-218.

25. Launberg P, Balow PI, Pederson KM, et al. Low incidence rate of overt hypothyroidism compared with hyperthyroidism in an area with moderately low iodine intake. Thyroid. 1999;9:80-88.

26. Flyn RW, Mac Donald TM, Morris AD, et al. The thyroid epidemiology, audit, and research study: thyroid dysfunction in the general population. J ClinEndocrinol 2004; 89:387984. 